\title{
Comparative risk assessment of potentially contaminated sites: proposal, implementation and application of a regional methodology
}

\author{
M. Marzocchini ${ }^{1}$, F. Tatàno ${ }^{2}$, M. S. Moretti ${ }^{2}$, C. Antinori ${ }^{2}$ \\ \& S. Orilisi ${ }^{1}$ \\ ${ }^{I}$ ARPAM - Regional Environmental Protection Agency, Marche Region, \\ Waste and Soil Service, Provincial Department of Ancona, Italy \\ ${ }^{2}$ DiGeoTeCA - Department of Geological Sciences, Chemical and \\ Environmental Technologies, University of Urbino "Carlo Bo", Italy
}

\begin{abstract}
A possible category within the soil and groundwater quality criteria for contaminated sites consists of the comparative (or relative) risk assessment. In the regulative and applicative Italian context of contaminated soil management, and with specific reference to the situation of potentially contaminated sites in Marche Region (Central Italy, Adriatic Sea side), this paper deals with the proposal of a possible simplified regional comparative risk assessment


"Marche Regional" basis) or equivalently in Italian "ACORI $\mathrm{I}_{\text {REG-M". }}$ " Following the description of the calculation structure and the computer worksheet

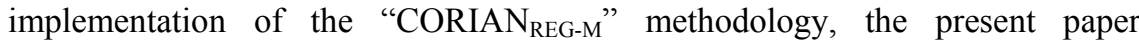
summarises also the application of this methodology to no. 12 potentially contaminated sites, which are located in Marche Region and represent diversified situations of potential contamination.
\end{abstract}

Keywords: application, comparative risk assessment, contaminated sites.

\section{Introduction}

Management of contaminated sites represents a major environmental challenge in many countries. Within an integrated plan (at a given territorial scale: provincial, regional, national, federal) for the identification, characterisation and 
final remediation of contaminated sites, an indispensable step certainly deals with the application of reliable and scientifically sound soil and groundwater quality criteria [1]. Specifically, a possible category of the soil and groundwater quality criteria for contaminated sites consists of the comparative (or relative) risk assessment [2]. This category of risk assessment can play a fundamental role in the management of potentially contaminated sites at a given territorial scale, providing - through the experimental data collected during site inspections and all the available documentation on the whole amount of suspected and/or registered sites - an evaluation of the hazard posed by each site in comparison to the others [3]. Thus, this evaluation of the comparative (relative) risk permits the definition of a priority list of the sites, which require further actions. Generally, these actions could be disaggregated as: 1) detailed site inspections and/or absolute, site-specific risk assessment [1], in the circumstance of the comparative risk approach applied to a given set of potentially contaminated sites; 2) remedial actions, under the alternative consideration of a consequential sub-set of truly contaminated sites. The priority list, as defined with a comparative risk assessment approach, can be useful for planning and financing of contaminated soil remediation, as the suspected and/or registered sites can be usually quite numerous (even hundreds or thousands), whilst the available financial budget (at provincial, regional, national or federal level) is limited in most cases.

As far as the Italian regulative situation is concerned, the temporal evolution of the national legislation on contaminated sites (Ministerial Decree No. “16/5/1989", Legislative Decree No. "22/1997”, Ministerial Decree No. "471/1999", and at present "Section IV" of Legislative Decree No. "152/2006") has always confirmed the requirement for defining "priority lists of actions" within the official "Regional Remediation Plans", thus providing a clear legal framework for the methodological application of the relative (comparative) risk assessment approach at regional levels. Moreover, the mentioned Italian Legislative Decree No. "152/2006" has properly defined as "potentially contaminated" those sites with measured contaminant levels in soil-subsoil and/or groundwater exceeding a generic list of expressly called "CSC, Contamination Threshold Values", with the consequential need of carrying-out a detailed site characterisation and subsequently a site-specific absolute risk assessment. Therefore, the procedural application of the comparative risk assessment approach at regional levels seems necessary in Italy already at the initial management phase of potentially contaminated sites.

In the above-synthesised regulative and applicative Italian context, and with specific reference to the situation of potentially contaminated sites in Marche Region (Central Italy, Adriatic Sea side), this paper deals with the proposal of a possible and simplified regional comparative risk assessment methodology, the

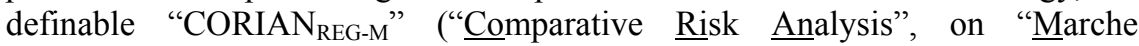
Regional" basis) or in Italian equivalently and initially named as "ACORI REG-M"

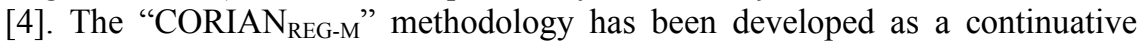
scientific cooperation between the contaminated soil group at the "ARPAM" Environmental Protection Agency of Marche Region (Department of Ancona) and the environmental-sanitary engineering unit at the University of Urbino 
"Carlo Bo". Following the synthetic description of calculation structure and

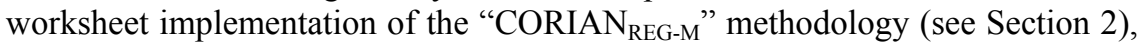
the paper also summarises (see Section 3) the methodology application to no. 12 potentially contaminated sites, which are located in Marche Region and represent diversified situations in terms of typologies of contamination source, detected contaminant chemical categories, active migration pathways and affected targets.

\section{2 “CORIAN REG-M" methodology: structure and worksheet implementation}

\subsection{General scoring procedure}

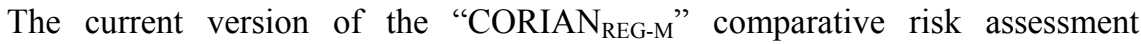
methodology takes into consideration three contaminant migration "pathways": "DC, Direct Contact”, "GW, Groundwater", and "A, Air”. Specifically, the air migration pathway has been further disaggregated in two sub-pathways, in order to evaluate simultaneously the possible different mechanisms of contaminant dispersion in the atmosphere, respectively: 1) the contaminant dispersion by volatilisation, as considered in the sub-pathway "Avol, Air volatiles"; 2) the contaminant dispersion by particulate emission, as considered in the complementary sub-pathway "Apart, Air particulate". Each of these considered migration pathways/sub-pathways (i.e., "DC", "GW", "Avol" and "Apart") is characterised by the following factor "categories": 1) "C $\mathrm{C}_{\mathrm{S}}$, Category Source" of contamination; 2) " $\mathrm{C}_{\mathrm{V}}$, Category Vector" of contamination; and 3) " $\mathrm{C}_{\mathrm{T}}$, Category Targets" potentially intercepted by the contamination. Then, each category includes two characterising " $\mathrm{F}$, Factors" (identified with "A" and "B" subscripts), whose scores (always with a maximum allowable value of 10), assigned to the given site and mathematically related among them by a simple arithmetical mean, contribute to the category score. Indeed, for the " $\mathrm{C}_{\mathrm{S}}$, Source Category" within the "Avol, Air volatiles" sub-pathway, the category scoring approach has been further disaggregated in accordance with the possible occurrence of contaminant volatilisation through the surface soil (usually $0-1 \mathrm{~m}$ from ground level [5]), the sub-surface soil (usually $-1 \mathrm{~m}$ to groundwater table level [5]), and the aquifer (see Section 2.2). Subsequently, the corresponding three category scores are multiplied, to obtain (in the numerical range $0-1,000$,

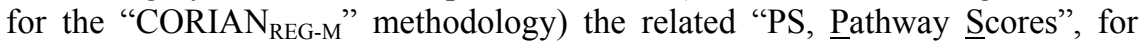
direct contact (namely, "PS-DC") and groundwater (namely, "PS-GW"), and

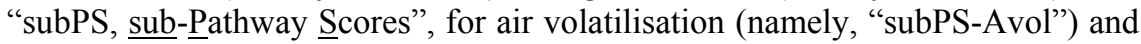
particulate emission (namely, "subPS-Apart"). Specifically, the air pathway score (namely, "PS-A") is then derived as the arithmetical mean of the corresponding sub-pathway scores "subPS-Avol" and "subPS-Apart" (see Section 2.2). Finally, the three pathway scores contribute to the site "CRI, Comparative Risk Index" (again in the numerical range 0-1,000), which is obtained with the following root-mean-square equation (similar to the original algorithm of both the internationally recognised U.S.EPA "HRS, Hazard Ranking System" and its simplified "PA-Score" version [6-9]): 


$$
C R I=\sqrt{\frac{(P S-D C)^{2}+(P S-G W)^{2}+(P S-A)^{2}}{3}}
$$

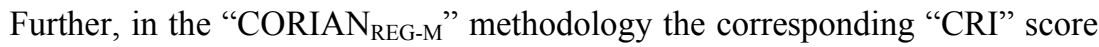
for each investigated site is associated to a simplified uncertainty coefficient,

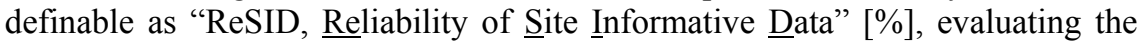
degree of reliability of available data on the given site in accordance with the following percentage expression [4]:

$$
\operatorname{ReSID}=\frac{(\text { no.tot.Fs. })_{\text {CORIAN }}-(\text { no.est } . F s .)_{\text {site }}}{(\text { no.tot.Fs. })_{\text {CORIAN }}} \times 100
$$

where "(no.tot.FS.) CORIAN" is the number of total Factors currently considered in

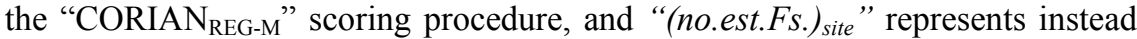
the number of particular evaluation factors whose scores - for the given site have been "estimated" with a non-optimal level of informative data.

\subsection{Considered pathways and related factors}

The scoring flow-chart of the "DC, Direct Contact" migration pathway is reported in Figure 1. The two factors taken into consideration in the " $\mathrm{C}_{\mathrm{S}}-\mathrm{DC}$ " source category for "DC" pathway are connected respectively with the nonpaved site surface interested by the potential contamination of top soil (factor " $\mathrm{F}_{\mathrm{S}}-\mathrm{DC}_{\mathrm{A}}$ "), and the original evaluation of the overall "intrinsic" hazardousness (factor " $\mathrm{F}_{\mathrm{S}}-\mathrm{DC}_{\mathrm{B}}$ ") for the contaminants detected in top-soil with documented concentrations exceeding the mentioned "CSC" screening levels (see Section 1).

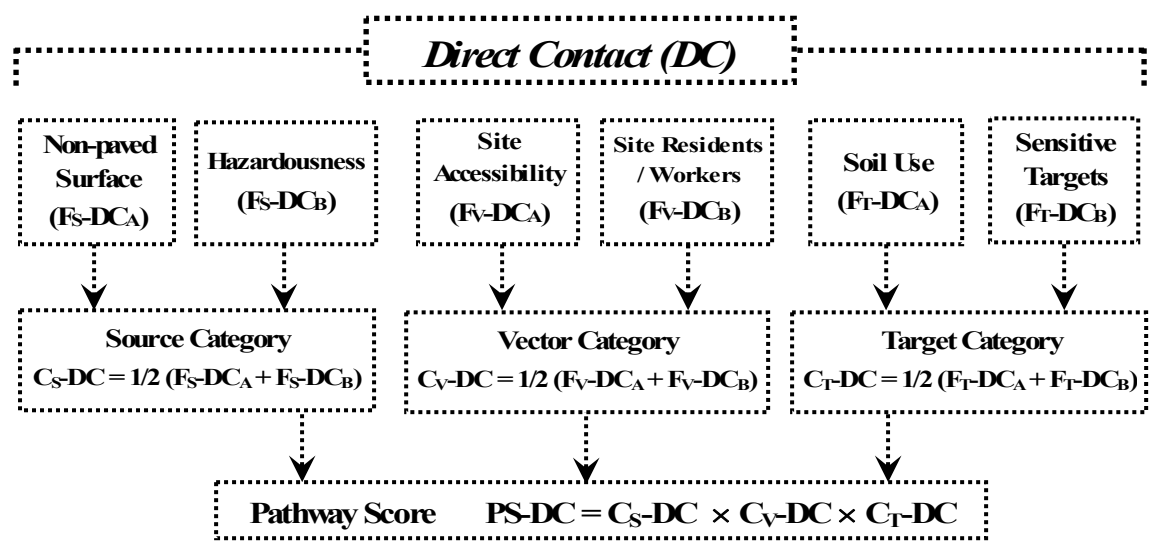

Figure 1: "CORIAN ${ }_{\text {REG-M }}$ " methodology: scoring flow-chart of "DC, Direct Contact" migration pathway. Legend: $\mathrm{F}=$ Factor; $\mathrm{C}_{\mathrm{S}}=$ Source Category; $\mathrm{C}_{\mathrm{V}}=$ Vector Category; $\mathrm{C}_{\mathrm{T}}=$ Target Category; $\mathrm{PS}=$ Pathway Score. 
Indeed, the hazardousness factor has been properly adapted to the source category of all considered migration pathways/sub-pathways of the

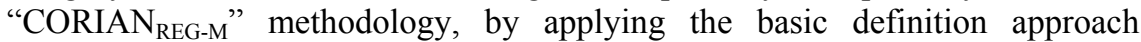
schematised in Figure 2. More specifically, and considering solely those contaminants exceeding the corresponding "CSC" screening levels (see Section 1) at the given site, the original aspect in defining the hazardousness factor is the ratio between the maximum contaminant concentration and the corresponding generic "Risk Threshold Value", named as "CSR" in the current Italian legislation on contaminated sites. Precisely, generic "CSR" values have been proposed by the Italian Environmental Protection Agency ("APAT", now "ISPRA") with the application of the official Italian methodological criteria for absolute risk assessment [10] to a generic site with "default" assumptions for the human exposure scenarios. Consistently, the approach of Figure 2 considers solely those generic "CSR" risk values which in turns result appropriate (in terms of: impacted soil, sub-soil or groundwater; human exposure pathways) for

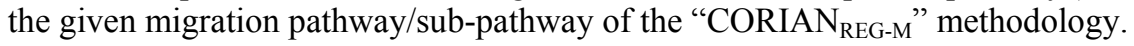

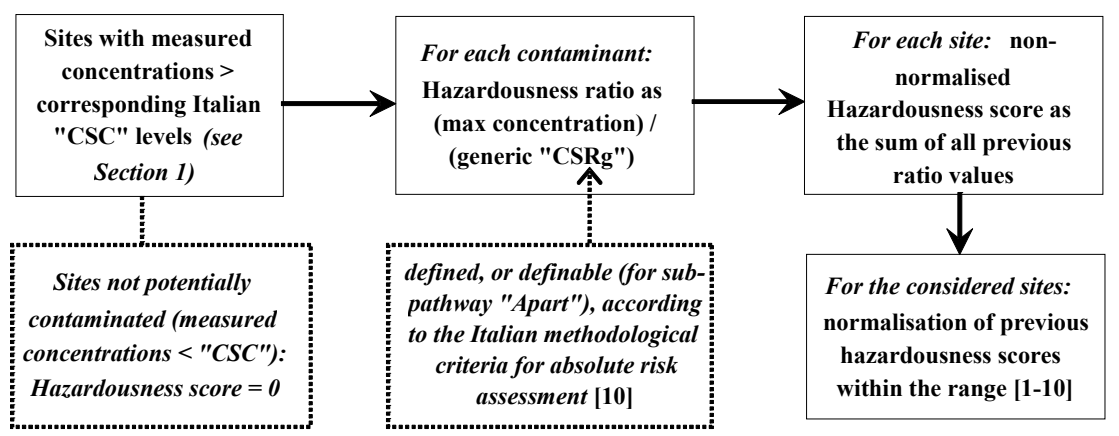

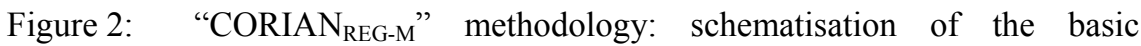
procedure adopted for the definition of the "Hazardousness factor" within the " $\mathrm{C}_{\mathrm{S}}$, Source Category" of the different migration pathways/sub-pathways. Legend: "CSC" = Italian Contamination Threshold Value; "CSRg” = Italian generic Risk Threshold Value.

With regard instead to the subsequent " $\mathrm{C}_{\mathrm{V}}-\mathrm{DC}$ " vector category for " $\mathrm{DC}$ " pathway, the considered factors simply concern with the site accessibility conditions (factor " $\mathrm{F}_{\mathrm{V}}-\mathrm{DC} \mathrm{C}_{\mathrm{A}}$ ") and the possible presence of on-site residents and/or workers (factor " $\mathrm{F}_{\mathrm{V}}-\mathrm{DC} \mathrm{C}_{\mathrm{B}}$ "). Lastly, the " $\mathrm{C}_{\mathrm{T}}-\mathrm{DC}$ " target category for " $\mathrm{DC}$ " pathway is comprehensive of the following factors: 1) the typology of land use in the site territorial area (residential/recreational, agricultural, commercial/industrial: factor " $\mathrm{F}_{\mathrm{T}}-\mathrm{DC}_{\mathrm{A}}$ "); 2) the possible presence of human sensitive targets (as schools, hospitals, human aggregation structures) within the selected distance of $500 \mathrm{~m}$ from the given site (factor " $\mathrm{F}_{\mathrm{T}}-\mathrm{DC} \mathrm{C}_{\mathrm{B}}$ ").

Figure 3 shows instead the scoring flow-chart of the "GW, Groundwater"

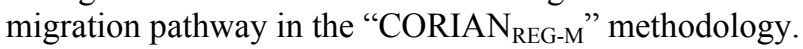




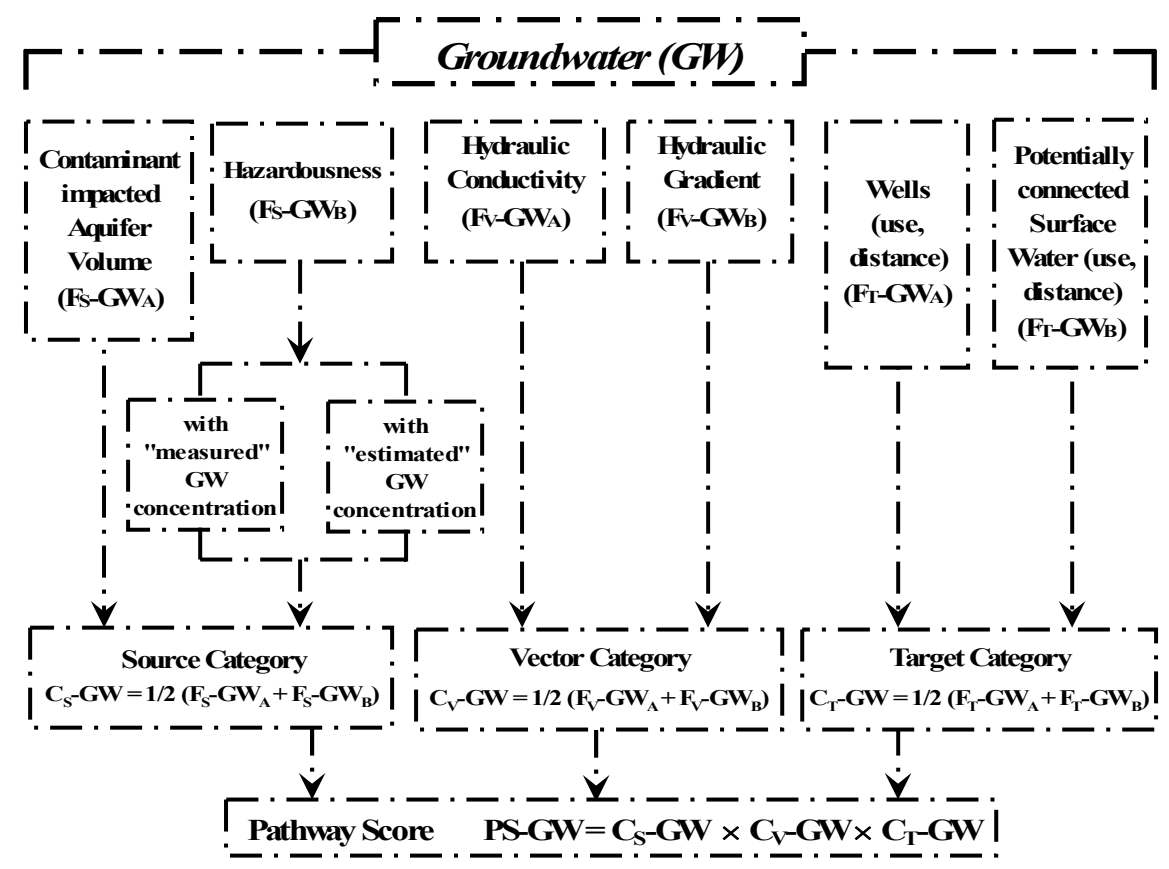

Figure 3: "CORIAN $\mathrm{REG}_{\mathrm{M}-\mathrm{M}}$ " methodology: scoring flow-chart of "GW, Groundwater" migration pathway. Legend: see Figure 1.

Firstly referring to the " $\mathrm{C}_{\mathrm{S}}-\mathrm{GW}$ " source category for " $\mathrm{GW}$ " pathway, the related factors consist of: 1) the volume of potentially contaminated portion of the aquifer (factor " $\mathrm{F}_{\mathrm{S}}-\mathrm{GW}_{\mathrm{A}}$ "); 2) the overall "intrinsic" hazardousness (factor " $\mathrm{F}_{\mathrm{S}}-\mathrm{GW}_{\mathrm{B}}$ ") as calculated, for those contaminants detected in groundwater with (measured, or in case estimated) concentrations above the mentioned groundwater "CSC" screening levels (see Section 1), according to the methodological approach of Figure 2. Then, the factors of the " $\mathrm{C}_{\mathrm{V}}-\mathrm{GW}$ " vector category for "GW" pathway are connected with the aquifer hydraulic conductivity (factor " $\mathrm{F}_{\mathrm{V}}-\mathrm{GW}_{\mathrm{A}}$ ") and gradient (factor " $\mathrm{F}_{\mathrm{V}}-\mathrm{GW}_{\mathrm{B}}$ "). Finally, the " $\mathrm{C}_{\mathrm{T}}-\mathrm{GW}$ " target category for " $\mathrm{GW}$ " considers the groundwater wells (with a mathematical combination of well use and inverse of well distance from the site: factor " $\mathrm{F}_{\mathrm{T}}-\mathrm{GW}_{\mathrm{A}}$ "), and cautiously also the surface water body in potential hydraulic connection with groundwater (with a proper combination of surface water use and inverse of distance from the site: factor " $\mathrm{F}_{\mathrm{T}}-\mathrm{GW}_{\mathrm{B}}$ ").

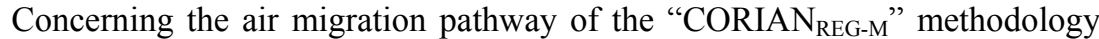
(Figure 4), its disaggregation in the volatile and particulate sub-pathways appears theoretically in line with the differentiation of inhalation of volatiles and fugitive dusts generally adopted in the international procedures for absolute risk assessment of contaminated sites (inter alia, the U.S.EPA "SSLs, Soil Screening Levels" protocol [11]). Thus, at first Figure 5 contains the scoring flow-chart for the "Avol, Air volatiles" migration sub-pathway. 


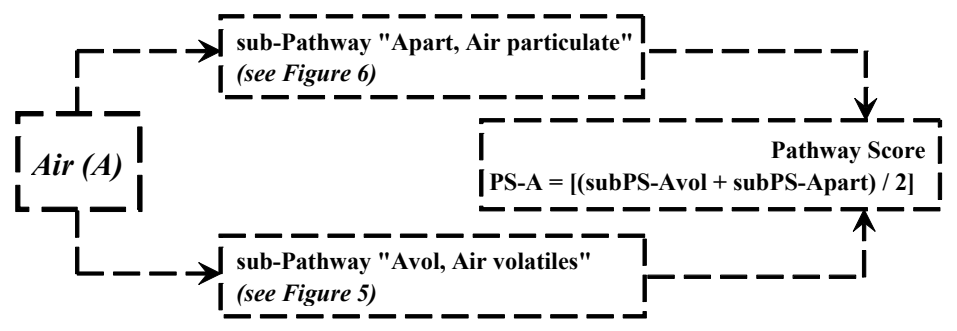

Figure 4: "CORIAN ${ }_{\text {REG-M }}$ " methodology: scoring of "A, Air" migration pathway, as disaggregated in the sub-pathways "Avol, Air volatiles" and "Apart, Air particulate". Legend: PS = Pathway Score; subPS = sub-Pathway Score.



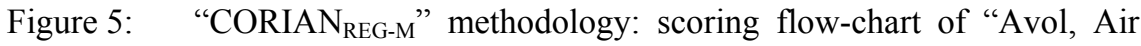
volatiles" migration sub-pathway. Legend: $\mathrm{F}, \mathrm{C}_{\mathrm{S}}, \mathrm{C}_{\mathrm{V}}, \mathrm{C}_{\mathrm{T}}=$ see Figure 1; ss = surface soil; sss $=$ sub-surface soil; $\mathrm{gw}=$ aquifer.

As mathematically shown in Figure 5 and mentioned in Section 2.1, the " $\mathrm{C}_{\mathrm{S}}$ Avol" source category for "Avol" sub-pathway considers the aggregation (by arithmetical mean) of the scoring approach with two factors, similar in definition to the previous pathways, simultaneously applied for the possible, concurrent 
contaminant volatilisation conditions from the affected surface soil, subsurface soil and groundwater [12]. The subsequent " $\mathrm{C}_{\mathrm{V}}$-Avol" vector category for "Avol" sub-pathway is instead based on the simple consideration of the lowest soil-air permeability in the vadose zone (factor " $\mathrm{F}_{\mathrm{V}}-\mathrm{Avol}_{\mathrm{A}}$ ") and the typology of site surface (paved, partially paved, unpaved: factor " $\mathrm{F}_{\mathrm{V}}-\mathrm{Avol}_{\mathrm{B}}$ "). Then, the conclusive " $\mathrm{C}_{\mathrm{T}}$-Avol" target category for "Avol" sub-pathway considers the following factors: 1) the typology of on-site land use and environment (indoor, outdoor, residential, commercial/industrial: factor " $\mathrm{F}_{\mathrm{T}}-\mathrm{Avol}_{\mathrm{A}}$ "); 2) the above mentioned possible presence of human sensitive targets (factor " $\mathrm{F}_{\mathrm{T}}-\mathrm{Avol}_{\mathrm{B}}$ ").

Secondly, Figure 6 shows the scoring flow-chart of the further air subpathway ("Apart, Air particulate"). On the conceptual analogy of previous pathways, the " $\mathrm{C}_{\mathrm{S}}$-Apart" source category for "Apart" sub-pathway considers the factors related with the potentially contaminated surface soil (factor " $F_{S}-A_{p} a r t_{A}$ ") and the overall contaminant hazardousness (factor " $F_{S}-A_{p a r t}$ ": see Figure 2). The " $\mathrm{C}_{\mathrm{T}}$-Apart" target category for "Apart" sub-pathway is characterised with the similar factors of "Avol" sub-pathway. On the contrary, the peculiarity of the " $\mathrm{C}_{\mathrm{V}}$-Apart" vector category for "Apart" sub-pathway relies on the following factors: 1) a particulate mobility factor [13], based on aridity De Martonne index (precipitation, temperature) and annual wind velocity (factor " $\mathrm{F}_{\mathrm{V}}$-Apart $\mathrm{A}_{\mathrm{A}}$ "); 2) the situation of on-site vegetation covering (factor " $\mathrm{F}_{\mathrm{V}}-$ Apart $_{\mathrm{B}}$ ")

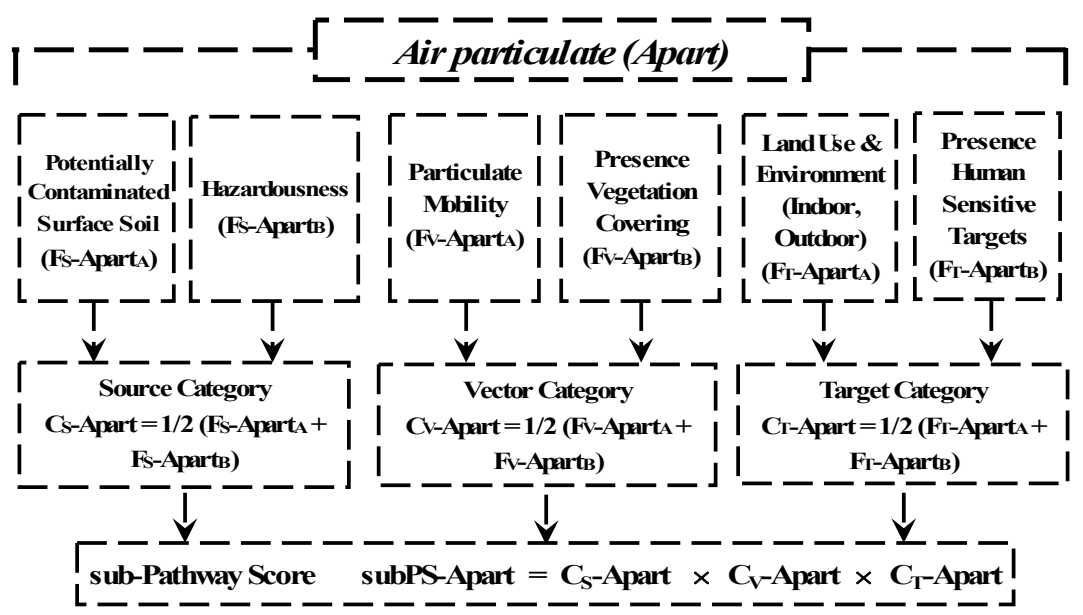


particulate" migration sub-pathway. Legend: $\mathrm{F}, \mathrm{C}_{\mathrm{S}}, \mathrm{C}_{\mathrm{V}}, \mathrm{C}_{\mathrm{T}}=$ see Figure 1.

\subsection{Computer worksheet implementation}

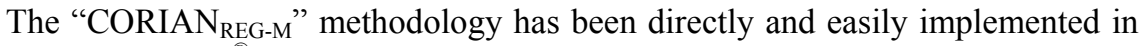
Microsoft Excel ${ }^{\mathbb{B}}$ format. Correspondingly, Figure 7 graphically summarises the considered and linked individual worksheets (iWSs). 




Figure 7: "CORIAN ${ }_{\text {REG-M }}$ " methodology: direct computer implementation in Microsoft Excel ${ }^{\circledR}$ format. Legend: iWS = individual worksheet; F = factor; ss, sss, gw = see Figure 5; CRI = Comparative Risk Index; generic CSR = generic "CSR, Risk Threshold Values", as defined in $[10]$; $\mathrm{CSC}=$ see Section 1; res = residential; ind $=$ industrial.

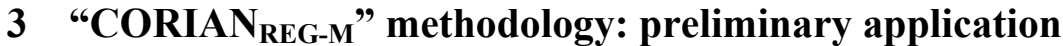


to no. 12 potentially contaminated sites located in Marche Region. Table 1 summarises the relevant characteristics of the considered "A-N" sites, which represent diversified situations in terms of: 1) typologies and extension of contamination sources; 2) detected contaminant chemical categories with concentrations exceeding the corresponding Italian "CSC" screening levels (see Section 1);3) possible combinations of potentially active migration pathways and affected human targets.

Correspondingly, the score diagrams of Figure 8 contain the overall results of

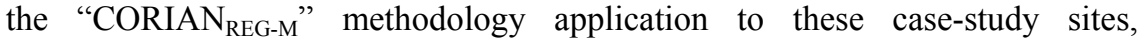
disaggregated in terms of individual pathway scores ("DC", "GW", "A") and final comparative risk index scores ("CRI"). The critical analysis of the score diagrams of Figure 8 synthetically permits some observations. 



sites. Legend: $\mathrm{CSC}=$ see Section 1; ISS = Italian Health Research Institute; res $=$ residential; com $/$ ind $=$ commercial/industrial; $\mathrm{DC}=$ Direct Contact; $\mathrm{GW}=$ Groundwater; $\mathrm{A}=$ Air.

\begin{tabular}{|c|c|c|c|}
\hline Site & Source typology & $\begin{array}{c}\text { Contaminants exceeding the corresponding } \\
\text { "CSC" levels (in the given environmental } \\
\text { medium) }\end{array}$ & $\begin{array}{c}\text { Potentially } \\
\text { active } \\
\text { pathways }\end{array}$ \\
\hline $\mathbf{A}$ & $\begin{array}{l}\text { Galvanic industrial } \\
\text { activity, out-of-date }\end{array}$ & $\begin{array}{l}\text { Cr tot, } \mathrm{Cr} \text { VI ( }>\text { CSC for soil }- \text { res \& com/ind, } \\
\text { and gw); } \mathrm{Pb}(>\mathrm{CSC} \text { for soil - res); } \mathrm{Ni}(>\mathrm{CSC} \\
\text { for } \mathrm{gw})\end{array}$ & $\begin{array}{l}\mathrm{DC}, \mathrm{GW}, \mathrm{A} \\
\text { (particulate) }\end{array}$ \\
\hline B & $\begin{array}{l}\text { Dump site with } \\
\text { pyritic ash waste }\end{array}$ & $\begin{array}{c}\mathrm{Cu}, \mathrm{As}(>\mathrm{CSC} \text { for soil - res \& com/ind }) ; \mathrm{Zn}(> \\
\text { CSC for soil - res) }\end{array}$ & $\begin{array}{c}\mathrm{DC}, \mathrm{A} \\
\text { (particulate) }\end{array}$ \\
\hline $\mathrm{C}$ & $\begin{array}{c}\text { Storage site of } \\
\text { wastes (pesticides) }\end{array}$ & $\begin{array}{c}\text { DDD, DDT, DDE ( }>\text { CSC for gw; > CSC for } \\
\text { subsoil - res \& com/ind) }\end{array}$ & $\begin{array}{c}\mathrm{GW}, \mathrm{A} \\
\text { (volatiles) }\end{array}$ \\
\hline D & $\begin{array}{l}\text { Machine shop, out- } \\
\text { of-date }\end{array}$ & $\begin{array}{c}\text { Total hydrocarbons ( }>\text { CSC for gw); } \\
\text { hydrocarbons } \mathrm{C} \leq 12,>12 \text { ( }>\text { CSC for subsoil } \\
\text { - res \& com/ind); MTBE ( }>\text { CSC for gw } \\
\text { proposed by the "ISS") }\end{array}$ & $\begin{array}{c}\mathrm{GW}, \mathrm{A} \\
\text { (volatiles) }\end{array}$ \\
\hline $\mathbf{E}$ & $\begin{array}{l}\text { Old solid waste } \\
\text { dump }\end{array}$ & $\begin{array}{l}\mathrm{Al}, \mathrm{Hg}, \mathrm{Ni}, 1,2-\mathrm{Dichloropropane}, 1,2- \\
\text { Dibromoethane (> CSC for gw) }\end{array}$ & $\begin{array}{c}\mathrm{GW}, \mathrm{A} \\
\text { (volatiles) }\end{array}$ \\
\hline $\mathbf{F}$ & $\begin{array}{l}\text { Old solid waste } \\
\text { dump }\end{array}$ & $\mathrm{Cr}$ tot, $\mathrm{Cu}, \mathrm{Pb}(>\mathrm{CSC}$ for soil-subsoil - res) & $\begin{array}{c}\mathrm{DC}, \mathrm{A} \\
\text { (particulate) }\end{array}$ \\
\hline G & Waste dump & $\mathrm{Cu}$, hydrocarbons $\mathrm{C}>12$ (> CSC for soil - res) & $\begin{array}{c}\text { DC, A } \\
\text { (volatiles, } \\
\text { particulate) }\end{array}$ \\
\hline H & $\begin{array}{l}\text { Old solid waste } \\
\text { dump }\end{array}$ & $\begin{array}{l}\mathrm{Fe}, \mathrm{Mn}, \text { Nitrite ( }>\text { CSC for gw); } \mathrm{NH}_{4}-\mathrm{N}(> \\
\text { CSC for gw proposed by the "ISS") }\end{array}$ & GW \\
\hline I & $\begin{array}{l}\text { Galvanic industrial } \\
\text { activity, out-of-date }\end{array}$ & $\begin{array}{l}\text { Cr tot, VI ( }>\text { CSC for soil }- \text { res \& com/ind); } \\
\text { Cd, Ni ( }>\text { CSC for soil - res); Ni ( }>\text { CSC for } \\
\text { gw) }\end{array}$ & $\begin{array}{l}\mathrm{DC}, \mathrm{GW}, \mathrm{A} \\
\text { (particulate) }\end{array}$ \\
\hline $\mathbf{L}$ & $\begin{array}{c}\text { Storage and } \\
\text { distribution of } \\
\text { kerosene and LPG }\end{array}$ & $\begin{array}{c}\text { Total hydrocarbons ( }>\text { CSC for gw); } \\
\text { hydrocarbons } \mathrm{C} \leq 12,>12 \text { ( }>\text { CSC for subsoil } \\
- \text { res } \& \text { com/ind })\end{array}$ & $\begin{array}{c}\mathrm{GW}, \mathrm{A} \\
\text { (volatiles) }\end{array}$ \\
\hline $\mathbf{M}$ & $\begin{array}{l}\text { Industrial site for } \\
\text { transformers, out- } \\
\text { of-date }\end{array}$ & $\begin{array}{l}\mathrm{PCB}, \text { hydrocarbons } \mathrm{C}>12(>\mathrm{CSC} \text { for soil - } \\
\text { res \& com/ind); tetrachloroethylene ( }>\text { CSC for } \\
\mathrm{gw})\end{array}$ & $\begin{array}{l}\mathrm{DC}, \mathrm{GW}, \mathrm{A} \\
\text { (volatiles, } \\
\text { particulate) }\end{array}$ \\
\hline $\mathbf{N}$ & $\begin{array}{c}\text { Service station site, } \\
\text { out-of-date }\end{array}$ & $\begin{array}{c}\text { Total hydrocarbons, benzene, toluene, } \\
\text { ethylbenzene, xylene, } \mathrm{Pb}(>\mathrm{CSC} \text { for gw); } \\
\text { benzene, xylene, hydrocarbons C } \leq 12 \text { ( }>\text { CSC } \\
\text { for subsoil - res \& com/ind); ethylbenzene, } \\
\text { toluene, hydrocarbons C }>12 \text { ( }>\text { CSC for } \\
\text { subsoil - com/ind); MTBE, ETBE, } \\
\text { trimethylbenzene ( }>\text { CSC for gw proposed by } \\
\text { the "ISS"); propylbenzene ( }>\text { CSC for gw in } \\
\text { the Italian "Giuditta" absolute risk analysis } \\
\text { tool) }\end{array}$ & $\begin{array}{c}\mathrm{GW}, \mathrm{A} \\
\text { (volatiles) }\end{array}$ \\
\hline
\end{tabular}

At first concerning "DC" and "A" pathway diagrams in Figure 8, site "B" comparatively shows the highest pathway scores, due to a large, non-paved potentially contaminated surface with consistent concentrations of some heavy metals and a sensitive residential-recreational use. At second referring to "GW" pathway diagram in Figure 8, site " $\mathrm{N}$ " is comparatively characterised by the first 
ranking position, due to diversified contaminants in the aquifer having consistent values of hydraulic conductivity and gradient. Lastly, the predominant ranking position of site " $\mathrm{B}$ ", significantly revealed for both the individual pathways "DC" and "A", is clearly confirmed in Figure 8 for the final "CRI" risk index.
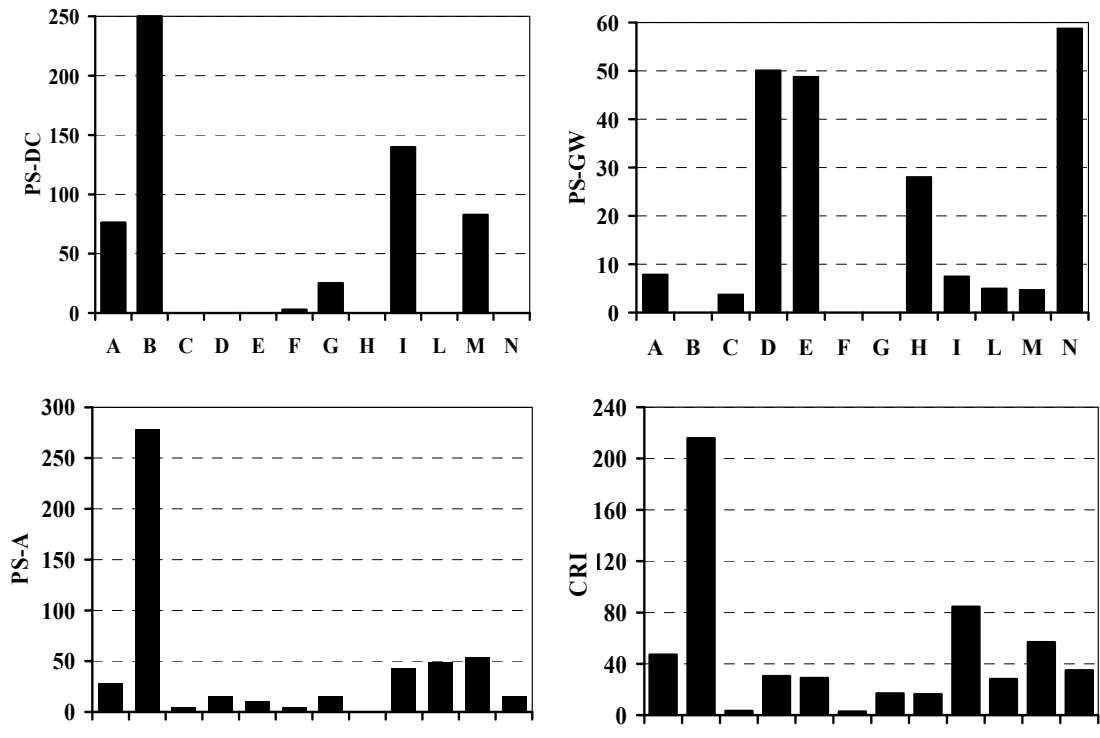

A

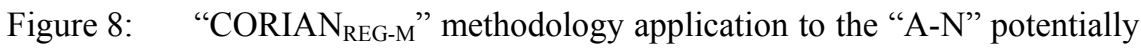
contaminated sites (see Table 1): pathway scores ("PS") for "DC, Direct Contact" (left-up), "GW, Groundwater" (right-up), “A, Air" (left-down), and final "CRI, Comparative Risk Index" (rightdown).

\section{Conclusions}

According to the temporal evolution of the national legislation on contaminated soil management (see Section 1), the activities of identification and registration of potentially and truly contaminated sites, and definition of priority lists for specific interventions to be carried out at these sites, are organised in Italy on a


2) has been developed and preliminarily applied (see Section 3), as a possible regional comparative risk assessment approach with reference to the multiannual management experience of potentially contaminated sites in Marche Region (Central Italy). The following aspects have been determinant in defining

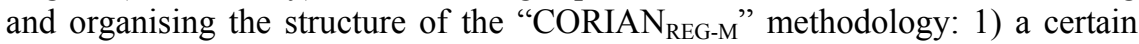
consistency in the modelling - necessarily simplified - of the mutual interactions "contamination source - migration pathways - receptors"; 2) the adaptation to the quality of informative data available on suspected and registered sites at the given regional scale; 3 ) the consideration of the direct experience and know-how 
on contaminated site identification and registration by the regional environmental agency responsible for contaminated soil management; 4) a fast, easy and clear procedure in the case of the expected periodical application of the methodology to the whole number of sites progressively inserted in the regional register; 5) the containment of financial budget necessary for the collection of site informative data requested by the methodology application; 6) the attempt for a certain conceptual linkage - as realised with "Hazardousness" factors in "C $\mathrm{C}_{\mathrm{S}}$ " source categories of the "CORIAN $\mathrm{REG}_{\mathrm{M}}$ " methodology (see Figure 2) with the current Italian methodological criteria for absolute risk assessment [10].

\section{References}

[1] D’Aprile, L., Tatàno, F. \& Musmeci, L., Development of quality objectives for contaminated sites: state of the art and new perspectives, Int. J. Environment and Health, Vol. 1, No. 1, pp. 120-141, 2007.

[2] D’Aprile, L., Marella, G. \& Tatàno, F., Comparative risk analysis for contaminated sites: Italian regional criteria in comparison with international standards, Brownfields Sites II: Assessment, Rehabilitation and Development, WIT Press, Southampton, pp. 53-62, 2004.

[3] Andreottola, G. \& Tatàno, F., Current status and perspectives in contaminated soil management, Proceedings of the "ISWA $25^{\text {th }}$ Anniversary World Congress on Waste Management”, Wien, 1995.

[4] Marzocchini, M., Antinori, C., Tatàno, F. \& Orilisi, S., Proposal of a regional criterion of comparative risk analysis for contaminated sites, $R S-$ Rifiuti Solidi, Vol. XXI, No. 4, pp. 208-225, 2007 (in Italian).

[5] D'Aprile L., Berardi, S. \& Baciocchi, R., Development of site-specific target levels for contaminated sites: Italian guidelines, Proceedings of “ConSoil 2008”, Milan, 2008.

[6] U.S.EPA, Hazard Ranking System (HRS): Final Rule, Federal Register, Rules and Regulations, Vol. 55, No. 241, pp. 51532-51667, 1990.

[7] U.S.EPA, Hazard Ranking System: Guidance Manual, Office of Solid Waste and Emergency Response, EPA 540-R-92-026, November, 1992.

[8] U.S.EPA, Guidance for performing preliminary assessments under CERCLA, EPA/540/G-91/013, September, 1991.

[9] National Research Council, Ranking hazardous-waste sites for remedial action, National Academy Press, Washington, DC, 1994.

[10] APAT, Methodological criteria for absolute risk analysis application at contaminated sites, Revised Version 2, March, Rome, available at http://www.isprambiente.it, 2008 (in Italian).

[11] U.S.EPA, Supplemental Guidance for Developing Soil Screening Levels for Superfund Sites, OSWER 9355.4-24, 2002.

[12] ASTM, Standard Guide for Risk-Based Corrective Action, E 2081-00, 2004.

[13] EEA, Towards an EEA Europe-wide assessment of areas under risk for soil contamination. Volume III: PRA.MS scoring model and algorithm, prepared by M. Falconi, F. Quercia, M. Schamann, T. Tarvainen, A. Vecchio, M. Wepner, Project manager A.R. Gentile, 2005. 